Nikken, P. (2018). Do (pre)adolescents mind about healthy media use: Relationships with parental mediation, demographics and use of devices. Cyberpsychology: Journal of Psychosocial Research on Cyberspace, 12(2), article 1. http://dx.doi.org/10.5817/CP2018-2-1

\title{
Do (pre)adolescents mind about healthy media use: Relationships with parental mediation, demographics and use of devices
}

\author{
Peter Nikken \\ Windesheim University of Applied Sciences, Zwolle, The Netherlands
}

\begin{abstract}
Some forms of media use may negatively affect (pre)adolescents' health, but little is known about the parent's role herein. Therefore, an online questionnaire among 1,741 Dutch youngsters (10-18 years) explored, a) whether they use electronic media in a healthy manner - i.e., no media during bedtime; no smartphones while cycling; lowering headset volume; taking breaks during extended media use; and keeping un upright posture during extended use, b) whether these healthy manners vary with their gender, education level, age and use of media devices, and c) whether their healthy media use varies with their parent's mediation. The analyses revealed that 'only' 11 to 30\% of (pre-)adolescents use media in a healthy manner. Moreover, as expected, pre-adolescents (10-12 years), adolescents from higher education and girls were more apt to use media in a healthy manner, as were frequent users of smartphones. Finally, (pre-)adolescents who are restricted in media use by their parents and who co-use media together with parents were about two times likely to use media in a healthy manner than youngsters whose parents are not involved. These outcomes imply that healthy media use deserves more attention within the framework of media-literacy and parental mediation.
\end{abstract}

Keywords: Health risk prevention; media use; restrictive parental mediation; active mediation; co-use

\section{Introduction}

Children and adolescents are using electronic screens a lot; in particular their smartphones, followed by TV sets, laptops, and tablets (Lauricella et al., 2016; Ofcom, 2017). However, both in the public debate and among scholars there are concerns about health risks associated with youngsters' media use (Gillespie, 2002). For instance, excessive smartphone use may end up in addictive-like behavior (Touitou, Touitou, \& Reinberg, 2016) or Compulsive Internet Use (CIU) (Vigna-Taglianti et al., 2017), which in turn may have negative effects on the child's development. Unthoughtful use of media among (pre)adolescents may also lead to sleep problems (George \& Odgers, 2015; Lemola, Perkinson-Gloor, Brand, Dewald-Kaufmann, \& Grob, 2015; Li, Lepp, \& Barkley, 2015). Furthermore, 'unwise' use may result in noise-induced hearing loss (Fligor, 2009; Portnuff, Fligor, \& Arehart, 2011; Vogel, Verschuure, van der Ploeg, Brug, \& Raat, 2009), headaches and digital eye stress (DES) (Rosenfield, 2016) and problems with musculoskeletal health (Cernikova, Smahel, \& Wright, 2017; Gillespie, 2006). Finally, the use of mobile devices may lead to distraction while cycling (Stelling-Kończak, Hagenzieker, \& Van Wee, 2015), and a declined health and well-being in general (Mathers et al., 2009). So far, scholars have often focused on the prevalence of these risky media behaviors and on how these behaviors are affected by psychosocial predictors, such as age, gender and educational level (e.g., Lemola et al., 2015; Vogel et al., 2009). Not many researchers have studied the role of parents for conscious, healthy media use by their children and, as far as they did, they mainly focused on one strategy that parents can apply: i.e., restrictions of their (pre)adolescents' media use. In practice, however, parents may also employ other strategies when guiding their children's media use. For example, making 
evaluative comments and providing assistance, a.k.a. active mediation, or experiencing media content and devices together, a.k.a. co-use (see Nikken, 2017a). Active mediation, in particular, is seen as a useful strategy to increase awareness and media literacy in children and adolescents (Mendoza, 2009), which hypothetically could result in more healthy media use too. A second problem in the research so far is that most studies are primarily conducted among adolescents of 12 years and older. Knowledge about younger, preadolescents' healthy media use is lacking, even though they also use media quite often (Ofcom, 2017; Rideout, 2017). In order to expand our knowledge on health-risk related media use, this study is the first to explore how several types of parental involvement, i.e., active and restrictive mediation and co-use, are associated with healthy media use by youngsters. Moreover, the respondents in this study represent youngsters aged 10 to 18 years, thus including preadolescents under 13 years as well.

\section{Theoretical Background}

Healthy media use. Research on (pre)adolescents' media use has indicated that certain users are more apt to engage with media technology in an unhealthy manner than others. Unhealthy media use, hereby, is defined as the usage of devices that may impair, directly or after a longer period, the physical development of the user (Gillespie, 2002), for example, prolonged media use in an uncomfortable posture, use at times when sleep is necessary, or use with earplugs at a harmful noise level. Healthy media use thus requires some sensibility from the user, akin to the necessity of a media-literate attitude when it comes to preventing risks and harm from media content or media contacts in the social-emotional domain (Livingstone, Mascheroni, \& Staksrud, 2015). Since a higher use of devices, together with more experiences with the pitfalls of media content and media contacts, may increase media-literacy (Livingstone \& Smith, 2014), a more healthy and sensible use of devices can be expected too when media devices are used more frequently. Moreover, physical experiences with one type of device, for instance headaches or backpain from wrongly using a laptop, could hypothetically also increase awareness of these health risks in other devices, for example a tablet or game console. However, a higher use of media devices may also increase the possibilities of wrong, unhealthy use. According to Gillespie (2006), for instance, frequent home computer use, i.e., daily use, increases the odds of neck and upper extremities symptoms of pain or discomfort in adolescents, as does computer use for longer periods without breaks. Furthermore, daily gamers and daily TV watchers reported more midback pain symptoms. Sustained and awkward postures assumed during extensive media use may thus generate musculoskeletal discomfort (e.g., Straker, Abott, Collins, \& Campbell, 2014). Given the lack of insight in how the frequency of the use of media devices may affect (pre-)adolescents' health, this study explores whether the use of different media devices is associated with more or less healthy media behaviors by (pre)adolescents $\left(R_{1}\right)$. Hereby, all common devices that youngsters use are incorporated, such as TV sets, phones, tablets, laptops or computers, and game consoles.

Healthy media use and background characteristics. Former studies have indicated that age is an important predictor of healthy media use by adolescents between 12 and 18 years. First, as compared to adults, these adolescents tend to listen to music with earphones at a higher, i.e. risky, volume (Fligor, 2009) and are more often woken up by incoming text messages at night (Lemola et al., 2015). Moreover, within the period of adolescence, specifically older adolescents, around 16 to 18 years, more often have their mobile switched on after lights out, make phone calls and send texts or engage in social media during bedtime, and more often watch TV in bed, than do younger adolescents, around 12 or 13 years (Lemola et al., 2015). Also, perhaps because of more autonomy, the older adolescents take fewer breaks in listening to music and are less likely to heed warnings against the risks of high-volume music than do younger adolescents, aged 12 to about 14 years (Vogel et al., 2009). In sum, it thus appears that within the period of adolescence unhealthy media use seems to increase with age. To what extent preadolescents, from about 10 to 12 years, use media in a healthy or unhealthy manner is unknown as far as I know. These preadolescents, however, often own smartphones and tablets too, or make use of other media technologies that are available via their parents at home (Lauricella et al., 2016). Therefore, this study focuses on preadolescents' healthy media use too.

Gender and types of educational level also are related to the use of media with consequences for healthy use. Especially older adolescent boys and boys from lower vocational schools report a higher prevalence of CIU as compared to older girls and adolescents from higher secondary educational levels (Vigna-Taglianti et al., 2017). Moreover, adolescents who attain lower vocational education are less aware of the risks of too loud music for their hearing than are adolescents in higher education (Vogel et al., 2009). Finally, boys are more apt to transgress 
rules about media use as compared to girls (Nikken \& Jansz, 2007), more often listen to music at a high risky volume than girls (Vogel et al., 2009) and more often watch TV or play games in bed during bedtime, though girls report more calling and/or text messaging in bed before sleep than boys (Lemola et al., 2015).

Given these findings for adolescents' background characteristics, I assume that healthy behaviors in media use are more often applied by preadolescents and younger adolescents as compared to older adolescents $\left(\mathrm{H}_{1 \mathrm{a}}\right)$, by girls as compared to boys $\left(\mathrm{H}_{1 b}\right)$, and by (pre)adolescents who attain higher secondary education as compared to lower, vocational educated (pre)adolescents $\left(\mathrm{H}_{1 c}\right)$.

Parental involvement in (pre)adolescents' media use. According to the EU Kids Online 'Risks and opportunities of digital media for children' model, social context is an important factor for how media devices are used and perceived by children (Livingstone et al., 2015, p.10). In this model parents have an important place, because with the appropriate type of involvement parents can influence which media their (pre)adolescents consume, determine which devices are allowed, instruct their children how to avoid risks, or show them the benefits that media may offer (Valkenburg, Piotrowski, Hermanns, \& de Leeuw, 2013). The parent's involvement in their children's media use, generally labeled as parental mediation (Nikken, 2017a), entails several strategies of which the three most essential are: a) co-use or shared media use for fun and entertainment by parents and children together; b) restrictive mediation, i.e., making agreements on when, where and what children can do with media; and c) active mediation, which according to some scholars (e.g., Weintraub Austin \& Pinkleton, 2001) may manifest itself in a positive form, i.e., stimulating critical thinking about media content, and in a negative dissenting form, i.e., disapproving of media content or warning for the negative effects that media can have.

As far as I know, only a few studies tested whether parental involvement affects healthy media use in (pre)adolescents. From these studies we may infer that restrictive mediation can result in beneficial health outcomes. Setting rules for e-game play at home, for example, relates to more healthy game habits (Straker et al., 2014), setting rules for internet content and time helps preventing CIU (van den Eijnden, Spijkerman, Vermulst, van Rooij, \& Engels, 2010), and limiting the possibilities of online peer-to-peer interactions either by time or by type of contacts is associated with reduced contact risks (Livingstone \& Helsper, 2008). The effectiveness of restrictive mediation on (pre)adolescents' healthy media use depends, however, on how parents apply their rules (Valkenburg et al., 2013). To be effective, parents and children both have to agree on the rules that are set (Straker et al., 2014) and the regulations should not be perceived by (pre)adolescents as too strict (van den Eijnden et al., 2010). Controlling online conversations, for instance, may lead to less risky contacts with unknown people and a more healthy life, but too strict ruling may also limit valuable contacts with peers and schoolmates, which ultimately may backfire on the parents (Valkenburg et al., 2013).

Unfortunately, so far, scholars have given little attention to how (pre)adolescents' healthy media use may be affected by their parents' active mediation or by co-using media devices. Only van den Eijnden and colleagues (2010) mention that active mediation, i.e., parental comments about excessive internet use, may curb CIU in adolescents. However, here too, the quality of the parents' comments is important. A lower risk of developing CIU is most prevalent among adolescents who feel comfortable, understood and taken seriously by their parents during conversations about the length of their internet use. Thus a positive attitude when applying active mediation may be more fruitful than a strict negative dissenting attitude.

Whether and how co-use may affect (pre)adolescents' healthy media use has not been studied yet, as far as I know. A reason for this void may be that co-use by itself is not considered effective in stimulating a media-literate attitude in adolescents, because using media for shared fun or entertainment does not necessarily stimulate critical thinking in children about what they consume (Mendoza, 2009). Parents, on the other hand, are a significant role model for their children (Nikken, 2017b) and adults use media more often in a healthy manner than adolescents (Fligor, 2009; Lemola et al., 2015). Moreover, as Livingstone and colleagues (2017) propose for contemporary digital devices co-use no longer just entails the passive consumption of media content, but also asks for active decisions, such as where and when to click or tap on the interactive screen. As such, the parents' behaviors during co-use may set an example for their children how to use media devices in a healthy manner. During shared media use, parents may, for instance, show that music doesn't have to be listened to at a very high volume. Also with parents present, children may more often sit in an upright position when watching a movie or when using a laptop, instead of hanging horizontally on the couch. 
Since parental mediation, and restrictive mediation in particular, may be associated with positive outcomes for children (Livingstone \& Helsper, 2008; Nikken, 2017a; Valkenburg et al., 2013), this paper theorizes that (pre)adolescents who experience more media involvement from their parents will make more healthy use of media than (pre)adolescents who receive less mediation from their parents. Thus, more healthy media use is expected among (pre)adolescents who co-use media more often with their parents together $\left(\mathrm{H}_{2 \mathrm{a}}\right)$, who are more restricted in their media use $\left(\mathrm{H}_{2 \mathrm{~b}}\right)$, and who receive more active mediation $\left(\mathrm{H}_{2 \mathrm{c}}\right)$.

\section{Method}

\section{Participants}

In the spring of 2015 an online questionnaire was presented to 1,741 (pre)adolescents between 10 and 18 years in the Netherlands after their parents had given consent to participate. The (pre)adolescents were pooled from a large database of respondents who had given assent to participate in (online) research by a professional research agency (TNS NIPO). In return for their cooperation they were paid a small incentive. Within the final sample 91.6 percent had a (smart)phone of their own, 58.2 percent also had a laptop, 54.8 percent owned a TV set, 51.5 a game console, and 46.6 percent owned a tablet. The mean age of the respondents was 14.14 years $(S D=2.58)$. There were somewhat more boys (51.8\%) than girls. With regard to educational type, 23 percent of the respondents attained primary education (their age varied from 10 to 13 years, mean age 10.7 years), 58.5 percent attained secondary education at a lower, vocational level (age varied from 11 to 18 years, mean 14.7), and 18.5 percent attained secondary education at a higher (pre-)university level (age varied from 14 to 18 years, mean 16.7). Regarding secondary education, the sample contained more respondents from vocational education as compared to figures from Dutch society (75\% versus 66\%) and less respondents from higher (pre-)university education ( $25 \%$ versus 34\%) (Nederlands Jeugdinstituut, 2017). The vast majority of the respondents (91.3\%) reported to classify themselves as Dutch, whereas 0.4 to 1.2 percent choose either Moroccan, Turkish, Surinamese, Antillean or Indonesian, and 4.8 percent picked 'other non-western' nationality. Because of the skewed spread of cultural background, and the possibility that 'Dutch' respondents could also stem from a Moroccan, Turkish or other family background, cultural ethnicity is not used in this study.

\section{Procedure}

At the start of the questionnaire, respondents were informed about the general aim of the study, i.e., an investigation about the role of media both for school and for youngsters' personal life. Also, they were informed about the initiator of the study: Mediawijzer.net, a national network organization with at that time about 1,100 members which promotes media-literacy in the Netherlands. The questionnaire was rather extensive; next to the questions about parental involvement in media use, (pre)adolescents' use and ownership of devices, and health issues, the questionnaire also touched on several other media related themes, such as: views about social (online) contacts, leisure time, hobby's, and home- and schoolwork. Because of the length of the questionnaire, with more than 300 items in total to be answered, most questions had simple yes-no response options. Answering all questions relevant for this paper took about twenty minutes for most of the respondents. Data collection was executed in accordance with guidelines formulated by the researchers' department's ethical review board.

\section{Measures}

Healthy use of media devices. Respondents were asked whether they deliberately do 10 specific things regularly to keep healthy (scored as 1 when yes, or 0 when not). Five of these behaviors referred to a healthy manner of media use (see Table 1). The 5 statements about healthy media use related to avoiding media use in traffic, sitting in an upright posture and taking regular breaks when using media, avoiding a risky volume when using earplugs, and avoiding media during bedtime. The items were specifically drawn up for this study, based on the general discourse in public about adolescents and health risks (e.g., Valkenburg \& Piotrowski, 2017) and the research mentioned in the introduction (e.g., Lemola et al., 2015; Stelling-Kończak et al., 2015; Vogel et al., 2009). The five items were moderately interrelated (Pearson's $r$ varied from .15 to .32; $p<.001$ ). Since we were interested in different healthy media use manners the single items are used in the analyses, instead of a scale constructed by collapsing the individual items. 
Use of media devices. Respondents indicated how frequently they used different devices, i.e., (smart)phones, TV sets, laptop/computers, game consoles, and tablets. Answering options for each device were respectively: 'never' (coded as 1), 'about once per month' (2), 'a few times per week' (3) and 'almost every day' (4). Respectively 82.5 and 73.9 percent used a smartphone and TV set almost every day, whereas 34.9 percent used a tablet, 16.8 a computer and 2.5 percent a game console on a daily basis. Only two respondents $(<0.1 \%)$ had indicated to 'never' use a TV, phone, tablet, laptop/computer, or game console.

Parental mediation. Based on former research (see Nikken, 2017a), perceived parental mediation was measured with 10 statements about parents' involvement with (pre-)adolescents' media use. These statements referred to the three main types of parental mediation: restrictive and active mediation, and co-use. Respondents indicated for each statement whether their parent regularly applied (1) or not applied (0) that form of mediation on their media use. An exploratory factor analysis with oblique rotation (i.e., direct Oblimin) resulted in four distinct factors. Using the items that had loadings higher than .45 (Tabachnick \& Fidell, 2007) on the respective factors, the following scales were constructed to measure parental involvement: a) restrictive mediation ( 3 items: no electronic media allowed during homework, no media during bedtime, no smartphones allowed during dinner time; $M=0.39, S D=0.28$, Cronbach's alpha $=.48$ ); b) dissenting active mediation ( 3 items: making comments about watching TV too long, gaming too much, using smartphone too long; $M=0.25, S D=0.31$, Cronbach's alpha $=.56$ ); c) positive active mediation ( 2 items, discussing what happened during surfing the internet, making agreements on 'good' apps to download; $M=0.19, S D=0.32, r=.30, p<.001$ ); and d) co-use ( 2 items, watching TV shows together, watching streamed movies together; $M=0.45, S D=0.36, r=.26, p<.001)$. Although the two scales with 3 items had rather low Cronbach's alpha values, all items within these scales correlated significantly; Pearson's $r$ varied between .23 and $.35, p<.001$. Also, in a theoretical sense the items within the scales seem to tap the same construct. Therefore, all four scales were used in the study.

\section{Analyses}

In order to test absolute differences between the prevalence of different types of healthy media behaviors in (pre)adolescents, paired $t$-tests were executed in SPSS 24. Next, absolute differences in prevalence between boys and girls, (pre)adolescents who attain different types of education, and younger and older (pre)adolescents, were tested by means of a series of ANOVA's. For the latter differences, the children were classified as 10-12 year-olds, 13-15 year-olds and 16-18 year-olds. Finally, the relative importance of the parental mediation strategies for (pre)adolescents' healthy media use was tested for each type of healthy behavior with logistic regression analyses. In these analyses other predictors were the child's gender, age and education, and the extent that they use different devices.

\section{Results}

\section{Prevalence of Healthy Media Use}

As shown in the last column of Table 1, in general, only a minority of the (pre)adolescents said that they consciously apply specific media use behaviors for their own health. About 1 in 3 (pre)adolescents deliberately shut down the computer or smartphone before going to sleep or taking a rest. Significantly less said that they lower the volume of their headphones or earplugs to an acceptable level when listening to music on their mobile devices, or deliberately do not use their smartphone for social media when riding their bike (Student's $t(1740)=$ respectively 2.85 and 2.90, $p$.010). Then, even significantly less (pre)adolescents, about 1 in 5 , said to take regular breaks when watching movies or TV series or playing games for longer periods $(t(1740)=6.24, p<.001)$, followed by only 1 in 8 (pre)adolescents who deliberately sit in a healthy upright posture at a desk or table when they use their laptop or tablet for an extended period of time $(t(1740)=6.43, p<.001)$. It should be noted, that when controlled for ownership of specific devices, such as smartphones or game consoles, the prevalence of the associated healthy behaviors in the subsamples of owners did not really change. Also, it is important to note that although the differences between the prevalence of healthy behaviors are significant, the effect sizes are all small according to Cohen's $d$, which varies between .07 and .24 . 


\begin{tabular}{|c|c|c|c|c|c|c|c|c|c|}
\hline & \multicolumn{3}{|c|}{ Age } & \multicolumn{3}{|c|}{ Education $^{a}$} & \multicolumn{2}{|c|}{ Gender } & \multirow[t]{2}{*}{ Total } \\
\hline & $10-12$ & $13-15$ & $16-18$ & Prim. & L-Voc & $\mathrm{H}$-sec & Boys & Girls & \\
\hline $\begin{array}{l}\text { Shutting down the computer or } \\
\text { smartphone before bedtime }\end{array}$ & 32 & 30 & 28 & 27 & 31 & 31 & 24 & $36 * \star *$ & $30 w$ \\
\hline $\begin{array}{l}\text { Not using a smartphone for } \\
\text { social media while driving a bike }\end{array}$ & 29 & 26 & 24 & 24 & 25 & 31 & 24 & $29 * *$ & $26^{x}$ \\
\hline $\begin{array}{l}\text { Lowering the volume of the } \\
\text { device when listening with } \\
\text { earplugs }\end{array}$ & 26 & 24 & 28 & 22 & 24 & $37 * * *$ & 21 & $31 * * *$ & $26^{x}$ \\
\hline $\begin{array}{l}\text { Taking breaks when playing or } \\
\text { watching for a longer period of } \\
\text { time }\end{array}$ & 22 & 15 & $18^{*}$ & 20 & 17 & 20 & 20 & 17 & $18^{y}$ \\
\hline $\begin{array}{l}\text { Sitting upright at a table when } \\
\text { using devices for a longer } \\
\text { period of time }\end{array}$ & 9 & 11 & $14^{*}$ & 8 & 12 & $15 *$ & 12 & 11 & $11^{z}$ \\
\hline
\end{tabular}

Note: ${ }^{\text {PPim. }}=$ primary education, $\mathrm{L}-\mathrm{voc}=$ lower vocational education, $\mathrm{H}-\mathrm{sec}=$ higher secondary education; Bold numbers indicate significantly distinct percentages from non-bold numbers within age, education or gender, $\sim p<.100 ; * p<.050, * * p<.010$, *** $p<.001$;

${ }^{w-z}$ Percentages with different superscripts in the Total-column are significantly different from each other.

Hypothesis 1 stated that taking preventive measures for healthy media use varies with (pre)adolescents' age, educational level and gender. Table 1 shows that $\mathrm{H}_{1 a}$ for age is not supported very well. Taking breaks during extended media use, and refraining from using smartphones while cycling, were indeed (marginally) more prevalent among the younger, preadolescents, than among adolescents of 13 years and older, $F(2,1738)=$ respectively $4.42, p<.050$ and $2.35, p<.100$. Sitting in an upright position when using media devices for longer periods was, however, more prevalent in older adolescents than in younger (pre)adolescents, $F(2,1738)=4.06, p<$ .050. Although, the differences for the three age groups were rather small or absent, ANOVA's with respondents' age per year interestingly revealed that in an absolute sense 12-year-olds were distinctly more engaged in most healthy media behaviors than all other respondents. Among the 12-year-olds no less than 41 percent said to turn off their devices before bedtime, $F(8,1732)=2.14, p<.050$. Another 38 percent reported to not use media on their bike, $F(8,1732)=3.12, p<.010$, and 24 percent said to take a break when watching TV series or playing games for extended periods, $F(8,1732)=2.19, p<.050$. In that light, $\mathrm{H}_{1 \mathrm{a}}$ is thus confirmed.

In line with $\mathrm{H}_{1 b}$, girls were more apt to deliberately shut down media devices before going to bed, adjust the volume of their portable music players, and refrain from using smartphones for social media while driving their bike than boys, $F(1,1739)=$ respectively 27.79 and $20.02, p<.001$, and $6.73, p<.050$. These gender differences are, however, not extensive, considering Cohen's $d$, which varies from .11 for not using a phone while cycling to .26 for not using media during bedtime.

Finally, confirming $\mathrm{H}_{1 c}$, adolescents in higher levels of secondary education more often said to deliberately lower the volume of their portable music players for their health than do children in lower levels of vocational education or in primary schools, $F(2,1738)=12.24, p<.001$. Also, higher secondary education students more often sit in an upright position when using media for an extended period of time and somewhat more often reported to refrain from using their devices while cycling than do children from lower vocational education or from primary education, $F(2,1738)=$ respectively $4.36, p<.050$, and 2.94, $p<.100$. According to Cohen's $d$, which varies between .11 and .29 , these differences indicate rather small effect sizes.

\section{Relative Differences in Healthy Media Use}

In order to test the associations between (pre)adolescents' healthy media use and their parents' involvement in their media use, together with background characteristics and the use of media devices, logistic regression analyses were used. These analyses make it also possible to control for potential confounding interrelationships between background variables, like for instance age and type of education. Table 2 shows the relationships for the five types of healthy media habits with the four parental mediation strategies, and the use of five devices and background characteristics. With regard to age, gender, and educational level, most of the expected differences were confirmed, though some changes appeared as compared to the absolute differences. For instance, as 
compared to preadolescents aged 10 to 12 years, adolescents aged 13 to 15 and aged 16 to 18 years now both less often lowered the volume of their hearing devices and less often refrained from using their phones or laptops during bedtime (now also confirming $\mathrm{H}_{1 \mathrm{a}}$ ). The analyses, however, did not indicate that adolescents of 16 years and older used media more often in a unhealthy manner than did adolescents aged 13 to 15 years. With regard to gender, the regressions again confirmed $\mathrm{H}_{1 b}$, i.e., girls more often than boys did not use their media devices during bedtime, or while riding their bike, and more often lowered the volume of their hearing devices. Finally, adolescents who attend higher education, significantly more often said to turn off their devices before going to sleep, to not use social media when riding a bike, to lower the volume of their hearing devices, and marginally to take breaks when using media for longer periods of time, than adolescents who attend primary education. In accordance with $\mathrm{H}_{1 c}$ these results were more pronounced for students in higher secondary education than for students from lower vocational education, i.e., adolescents from higher education were about twice as likely to use media in a healthy manner than were students from vocational education.

Table 2. Logistic Regression Analyses Using Background Characteristics, Media Use and Types of Perceived Parental Mediation to Predict Absence (0) or Presence (1) of Healthy Media Use Manners.

\begin{tabular}{|c|c|c|c|c|c|c|c|c|c|c|}
\hline & \multicolumn{2}{|c|}{ No media at bedtime } & \multicolumn{2}{|c|}{ No media on a bike } & \multicolumn{2}{|c|}{ Lowering volume } & \multicolumn{2}{|c|}{ Taking regular breaks } & \multicolumn{2}{|c|}{ Sit upright at table } \\
\hline & $\operatorname{Exp}(B)$ & {$[95 \% \mathrm{Cl}]$} & $\operatorname{Exp}(B)$ & {$[95 \% \mathrm{Cl}]$} & $\operatorname{Exp}(B)$ & {$[95 \% \mathrm{Cl}]$} & $\operatorname{Exp}(B)$ & {$[95 \% \mathrm{Cl}]$} & $\operatorname{Exp}(B)$ & {$[95 \% \mathrm{CI}]$} \\
\hline \multicolumn{11}{|c|}{ Background characteristics } \\
\hline $13-15$ year-olds ${ }^{a}$ & $.56 * *$ & {$[.38-.81]$} & $.43^{* * *}$ & {$[.29-.63]$} & $.55^{\star *}$ & {$[.37-.82]$} & $.51 * \star$ & {$[.33-.79]$} & 1.09 & {$[.61-1.97]$} \\
\hline $16-18$ year-olds $^{a}$ & $.53^{\star \star}$ & {$[.35-.80]$} & $.36 * * *$ & {$[.23-.54]$} & $.54 * \star$ & {$[.35-.84]$} & $.63 \sim$ & {$[.39-1.03]$} & 1.31 & {$[.70-2.45]$} \\
\hline Lower voc. educ. ${ }^{b}$ & $1.80 * *$ & {$[.27-.79]$} & $1.70 *$ & {$[1.10-2.63]$} & $1.52 \sim$ & {$[.97-2.38]$} & 1.39 & {$[.85-2.27]$} & 1.13 & {$[.57-2.25]$} \\
\hline Higher sec. educ. ${ }^{b}$ & $2.19 * *$ & {$[1.16-2.77]$} & $3.07 * \star \star$ & {$[1.77-5.31]$} & $2.92 * \star *$ & {$[1.68-5.09]$} & $1.85 \sim$ & {$[.99-3.44]$} & 1.18 & {$[.53-2.64]$} \\
\hline Gender $^{c}$ & $1.65 * * *$ & {$[1.27-3.76]$} & $1.31 *$ & {$[1.03-1.67]$} & $1.65^{* * *}$ & {$[1.29-2.10]$} & .91 & {$[.69-1.20]$} & .86 & [.62-1.19] \\
\hline \multicolumn{11}{|l|}{ Media use } \\
\hline Smartphones & $1.29 * *$ & [1.09-1.52] & $1.57 * \star \star$ & {$[1.30-1.91]$} & $1.20 *$ & {$[1.01-1.43]$} & 1.04 & [.87-1.23] & 1.15 & [.89-1.48] \\
\hline TV's & .98 & [.84-1.13] & 1.05 & {$[.89-1.23]$} & $.83^{*}$ & [.72-.97] & $.77^{\star \star}$ & [.65-.91] & .93 & [.76-1.14] \\
\hline Tablets & 1.01 & [.92-1.10] & .98 & [.89-1.08] & 1.01 & {$[.92-1.11]$} & 1.00 & {$[.90-1.12]$} & 1.00 & [.87-1.13] \\
\hline Computers & 1.07 & {$[.91-1.26]$} & .95 & {$[.80-1.13]$} & 1.06 & [.89-1.26] & 1.01 & [.83-1.22] & $1.99 * * *$ & [1.56-2.52] \\
\hline Game consoles & .96 & {$[.81-1.14]$} & 1.14 & {$[.95-1.36]$} & 1.10 & [.92-1.32] & $1.44 * \star \star$ & [1.18-1.74] & .84 & {$[.66-1.08]$} \\
\hline \multicolumn{11}{|l|}{ Parental mediation } \\
\hline Restrictive & $2.38 * * *$ & [1.58-3.60] & $1.89 * \star$ & {$[1.23-2.89]$} & 1.07 & {$[.70-1.65]$} & 1.20 & [.74-1.95] & $1.71 \sim$ & {$[.95-3.08]$} \\
\hline Dissenting active & 1.03 & {$[.72-1.47]$} & 1.06 & {$[.73-1,53]$} & 1.10 & {$[.76-1.60]$} & .90 & {$[.59-1.37]$} & .88 & [.53-1.47] \\
\hline Positive active & 1.29 & {$[.90-1.85]$} & .96 & {$[.65-1.40]$} & .80 & [.54-1.19] & 1.09 & {$[.71-1.66]$} & 1.22 & {$[.71-2.03]$} \\
\hline Co-use & $1.98 * * *$ & [1.46-2.68] & $1.81 * \star *$ & {$[1.32-2.48]$} & $2.37 * \star \star$ & {$[1.73-3.25]$} & $2.98 * \star \star$ & [2.09-4.25] & $1.83^{* \star}$ & {$[1.20-2.80]$} \\
\hline $\operatorname{Chi}^{2}(14)$ & $109.60 * * *$ & & $105.29 * * *$ & & $90.87 * \star \star$ & & $71.64^{\star \star *}$ & & $57.31 * \star \star$ & \\
\hline
\end{tabular}

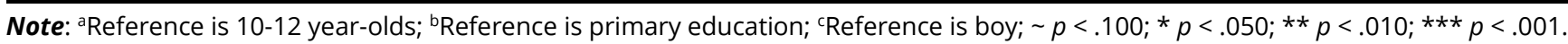

According to the regression analyses, the frequency by which (pre)adolescents make use of different devices also had some impact on their healthy media behaviors $\left(R Q_{1}\right)$. The use of smartphones was associated with less use of media devices during bedtime or when riding a bike, and more often lowering the volume of headsets. More use of computers and of game consoles was also positively associated with sitting upright at a table or desk and with taking breaks when using media for longer periods, respectively. For the use of TV sets, however, another pattern appeared: (pre)adolescents who watch more TV less often take breaks when using media for longer periods and also less often lower the volume of their devices.

With regard to parental involvement, Table 2 shows that $\mathrm{H}_{2}$ is partly confirmed. Children who co-use media regularly together with their parents significantly more often said to apply all types of healthy media behaviors (in accordance with $\mathrm{H}_{2 \mathrm{a}}$ ). The chance that they use media in a healthy way is about 2 to 3 times higher than when their parents do not use media regularly with them together. Also, (pre)adolescents who were restricted in their media use by their parents would turn off their devices more often before bedtime and not use their devices for social media while driving a bike, and also tended to sit more often in a healthy posture when using the computer for a longer period (confirming $\mathrm{H}_{2 \mathrm{~b}}$ ). Again, the chances that they would use media in such a responsible manner are about 2 times higher than when their parents did not put restrictions on their media use. Dissenting active 
mediation, i.e., minding the child that he or she is using media devices too long, and positive active mediation did not affect any of the five habits of healthy media use (thus not confirming $\mathrm{H}_{2 c}$ ).

\section{Discussion}

This study explored relationships between (pre)adolescents' deliberate actions for healthy media use and their parents' involvement in media use. As far as I know, scholars have mainly studied the effect of parental restrictions on adolescents' media use (e.g., Livingstone \& Helsper, 2008; van den Eijnden et al., 2010), whereas little attention has been given to parents' active mediation or co-using media together with their children in relationship to healthy use of devices. It was expected that children who experience more parental mediation, are more apt to deliberately a) turn off devices before bedtime, b) lower the volume of hearing devices when listening to music, c) refrain from using social media on their smartphone while riding a bike, d) take breaks when watching or gaming for longer periods, and e) sit in an upright posture at a table or desk when working for longer periods on media devices, for their own health. Also, it was assumed that girls, younger (pre)adolescents, and adolescents who attain higher levels of education would use media more often in a healthy manner as compared to boys and to older and lower educated (pre)adolescents. Finally, this study also explored whether frequent use of media devices is associated with healthy media use. Four interesting findings emerged from this study.

\section{Low Prevalence of Risk Preventive Behaviors}

In the first place, the results showed that (pre)adolescents, in general, do not often use media deliberately in a healthy manner. Turning smartphones and laptops off before and during bedtime was done by about one in three youngsters. This amount is in between the $26 \%$ of German adolescents who never communicate by phone or text and the $41 \%$ who are never online via Facebook or chat communities before bedtime, as reported by Lemola et al. (2015). Deliberately not using social media on a smartphone during cycling was practiced by only 26 percent of the (pre)adolescents. Since practically all Dutch youngsters ride a bike, three quarters of children between 10 and 18 years may jeopardize their health by using their smartphones for social media activities while driving, which is distinctly more than 42 percent of the adult Dutch population who do not provide conversations by phone or 52 percent who refrain from listening to music on their bike (Stelling-Kończak et al., 2015). Lowering the volume of earplugs consciously also was done by less than three in ten (pre)adolescents, which is considerably more than the $7 \%$ who use noise-limiters according to Vogel et al. (2009). However, conversely, again still about 70 percent of youngsters may risk a too high volume which could eventually result in hearing loss (Portnuff et al., 2011). Taking a break during longer lasting sessions of media use and sitting in a healthy posture during extended use of devices was practiced deliberately by 'only' about one in five and, respectively, one in eight (pre)adolescents. Since almost all youngsters at least had their own (smart)phone or another device and had indicated to use these media devices mostly on a daily basis, it is of high concern that so few (pre)adolescents seem to use media in a healthy manner. More research in children's healthy media use is therefore warranted, preferably using more extended and validated measures than was available in the present data. Scholars may gather more information in youngsters on how they deal with negative health effects of, for instance, repetitive button clicking or awkward wrist movements; prolonged bouts of sedentary behavior which may lead to musculoskeletal health disturbances, in particular, lower back pain and or obesity; prolonged looking down at smart-screens which may result in neck pain; or too dark or too bright screens which may give problems in eye sight. Moreover, with the ubiquitous presence of digital mobile devices in the life of (pre-)adolescents the theory of media-literacy and parental mediation should be extended too to physical risks and benefits, next to risks and chances of media content and contacts for the cognitive and social-emotional development of children.

\section{Parents as Role Models and Gatekeepers}

Second, former research (van den Eijnden et al., 2010) indicated that parental negative comments on adolescents' extended media use helps to curb unhealthy media use, but our results do not confirm these findings. Dissenting mediation was not related to healthy media behaviors. Also, contrary to what was expected, positive discussions about media were not clearly related to less risky media use too. The absence of relationships may, however, be explained by the nature of both strategies as measured in this study. In hindsight, the two positively formulated active mediation items in this study (discussing online experiences and informing about 'good' apps) were perhaps not specific enough to measure parents' intentions to stimulate (pre)adolescents' awareness about healthy use of 
devices. Also, the respondents in the present study were not per se at a high risk of addictive media use, like the adolescents in the van den Eijnden and colleagues (2010) study. Perhaps therefore, dissenting active mediation may not have been convincing enough for the (pre)adolescents to adapt their use of media devices, moreover as they may have perceived media as their personal domain over which parents have no legitimacy (Valkenburg et al., 2013).

Despite the absence of relationships with both active mediation measures, the results, however, still do indicate that parents are influential as was hypothesized. When parents put clear restrictions on their children's media use, they less often operate their media devices during bedtime or when riding a bike and tend to sit in a more healthy posture when using media for longer periods. Moreover, co-use of media, i.e., watching films and TV series together with parents, was also strongly paralleled by a higher prevalence of all healthy media use habits. These results are of interest for practitioners and other professionals in the domain of parenting support. Apparently, a parent's involvement in their children's media use may pay off, when it is overtly aimed at preventing unhealthy or potentially dangerous media habits that may result in poor sleep, traffic accidents or musculoskeletal problems, or when it is based on the mutual enjoyment of media content. Perhaps, making agreements via restrictive mediation has a more direct effect on (pre)adolescents' thinking about their own health and safety than dissenting active mediation. How co-use affects healthy media habits in (pre)adolescents cannot be inferred from our data, but perhaps parents present a healthy and trustworthy role model for their children when using media together, which in turn may affect (pre)adolescents' awareness of healthy use of devices. Guidelines, programs or interventions aimed at stimulating healthy media use in children should thus take account of the important role of parents. Akin to campaigns that aim to keep (pre)adolescents from smoking or from alcohol drinking, parental mediation advice for parents should also focus on how parents' media behaviors function as a role model for their children.

\section{Some Adolescents More at Risk}

Thirdly, as hypothesized, girls were more thoughtful about risky media use than were boys, as were higher educated adolescents as opposed to adolescents who attain lower education. The finding that children from higher educational levels were more aware of unhealthy media use corroborates earlier work by Vogel and colleagues (2009) and Vigna-Taglianti and colleagues (2017). Why (pre)adolescents from lower educational levels care less about their health cannot be inferred from the present data, but these children usually also are more prone to health risks in general (Sweeting \& Hunt, 2014) and may also have less developed media-literacy skills (Livingstone, Haddon, Görzig, \& Ólafsson, 2011). This warrants for more attention to health issues in media-literacy programs, specifically interventions aimed at (pre)adolescents from lower educational levels. The higher prevalence of many risk preventive behaviors among girls also fits with earlier findings showing that males are more risk taking, both in general (Byrnes, Miller, \& Shafer, 1999) and when it comes to media use (Nikken \& Jansz, 2007; Vogel et al., 2009). Apparently, minding about the effects of media use for hearing loss, traffic accidents, or poor sleep seems less important for boys than for girls, which also warrants for specific attention in media-literacy interventions.

Interestingly was the finding that more use of specific media devices was paralleled by more conscious use of these devices. Frequent users of smartphones, for instance, less often used media during bedtime, on their bike, and more often thought about lowering the volume of the headset. Users of computers and game consoles more often minded about breaks and posture during their use. These results indicate that a higher use of media leads to more experience and with more experience more awareness about the risks. Consciousness about health risks may thus develop in the same way as awareness about contact and content risks develops with more media experience (Livingstone \& Smith, 2014). The use of TV sets, however, was negatively related to (pre-)adolescents awareness of high volume risks and watching or gaming for extended periods. More research into media use motivations and health risk perceptions in adolescents is needed for grounded conclusions, but the high interest among youngsters today in binge-watching series on platforms like Netflix may explain the latter outcome. Modern offerings of television content on Netflix and other contemporary video-on-demand technologies and online games may increase the risk of extended media use. Therefore, more attention to intervention strategies that aim to break up adolescent's bouts in binge-watching or binge-gameplaying may be necessary (Straker et al., 2014). As this study shows it seems necessary that such new intervention strategies and pedagogical advice about healthy media use could focus on taking breaks instead of advising a maximum of screen time per day, in order to be 
effective among (pre)adolescents. At the moment, most efforts that aim to curb children's extensive media consumption frame that use primarily as compulsive or as an addiction, and usually propose rather drastic restrictions instead of just taking regular breaks (Mathers et al., 2009; Vigna-Taglianti et al., 2017). As a matter of fact, parents may gain from a break-approach too. For parents it may be easier to negotiate with their children about sessions of media use with regular breaks, than to set strict time limits per day for their children. Such strict time limits may be interpreted as a denial of what media mean in a positive sense for (pre)adolescents (Valkenburg et al., 2013).

Finally, in the fourth place, this study specifically incorporated preadolescents from 10 to 12 years, as opposed to most former studies on healthy media use that only had respondents older than 12 years. Interestingly, the preadolescents and especially the 12-year-olds were most apt to report preventive strategies in their media use. This finding can be explained by two facts. First, in most western countries children usually get their own media devices, such as laptops, tablets and smartphones when they are between 10 and 12 years old (GSMA, 2014; Ofcom, 2017). In the Netherlands indeed about 70 percent of 10-year-old children own a smartphone, whereas practically all children have one when they start to attend secondary education at the age of 12 or 13 (Boeke, Dondorp, Heitink, \& Pijpers, 2017; Jeugdjournaal, 2016). Secondly, when these children start secondary education, they usually have to travel distinctly longer distances to school, mostly by bike. Perhaps these two big changes in the child's life help in raising awareness about safe and conscious media use. As the data show, however, this media-awareness seems to wane when adolescents get older. Advice for parents by practitioners on healthy media use, such as by the American Association of Pediatrics (Radesky \& Christakis, 2016), should thus not only focus on families with young children or younger preadolescents, but also on older adolescents.

\section{Limitations}

For scholars, the findings from this study warrant for further research. Unfortunately, the measures in this study were limited, for example, either by the number of items or by simple yes-no answering options for the respondents. Also, respondents could not skip questions or denote 'not relevant' in case a question was not applicable to the respondent's situation. Although unlikely, some youngsters may therefore have indicated to not use media in a healthy manner, because they do not use media at all in a specific situation, for instance, while riding a bike. As stated before, new research may also look at more types of risky media use, for example, behaviors in relation to eye-sight problems, headaches or spinal problems, and preferably use measures that are not binary like in the present study. Moreover, it would be interesting to also gather information about (pre)adolescents' knowledge about and motivations for using media in a healthy or risky manner, and about what they think about their parents' mediation activities. Finally, future studies should also explore new measures of parental involvement, i.e., focusing more on mediating physical health in children's media use. The results of the present study provide an interesting starting point for such research which may strengthen our knowledge of health related media-literacy skills in children.

\section{References}

Boeke, H., Dondorp, L., Heitink, M., \& Pijpers, R. (2017). Monitor Jeugd en media 2017 [Monitor youth and media 2017]. Zoetermeer: Kennisnet.

Byrnes, J. P., Miller, D. C., \& Shafer, W. D. (1999). Gender differences in risk taking: A meta-analysis. Psychological Bulletin, 112, 367-383. https://doi.org/10.1037/0033-2909.125.3.367

Cernikova, M., Smahel, D., \& Wright, M. F. (2017). Children's experiences and awareness about impact of digital media on health. Health Communication, 33, 664-673. http://dx.doi.org/10.1080/10410236.2017.1298197

Fligor, B. J. (2009). Personal listening devices and hearing loss: Seeking evidence of a long term problem through a successful short-term investigation. Noise Health, 11, 129-131. https://doi.org/10.4103/1463-1741.53356

George, M. J., \& Odgers, C. L. (2015). Seven fears and the science of how mobile technologies may be influencing adolescents in the digital age. Perspectives on Psychological Science, 10, 832-851.

https://doi.org/10.1177/1745691615596788 
Gillespie, R. M. (2002). The physical impact of computers and electronic game use on children and adolescents: A review of current literature. Work, 18, 249-225.

Gillespie, R. M. (2006). CAKE (Computers and Kids' Ergonomics): The musculoskeletal impact of computer and electronic game use on children and adolescents, Dissertation. New York University.

GSMA (2015). Children's use of mobile phones: A special report 2014. Japan: GSMA/NTT Docomo.

Jeugdjournaal (2016). Het grote mobieltjes-onderzoek [The great mobile phone study]. Hilversum: NOS Jeugdjournaal. Retrieved from https://jeugdjournaal.nl/artikel/2148366-het-grote-mobieltjes-onderzoek-van-hetjeugdjournaal.html

Lauricella, A. R., Cingel, D. P., Beaudoin-Ryan, L., Robb, M. B., Saphir, M., \& Wartella, E. A. (2016). The Common Sense census: Plugged-in parents of tweens and teens. San Francisco, CA: Common Sense Media.

Lemola, S., Perkinson-Gloor, N., Brand, S., Dewald-Kaufmann, J. F., \& Grob, A. (2015). Adolescents' electronic media use at night, sleep disturbance, and depressive symptoms in the smartphone age. Journal of Youth \& Adolescence, 44, 405-418. https://doi.org/10.1007/s10964-014-0176-x

Li, J., Lepp, A., \& Barkley, J. E. (2015). Locus of control and cell phone use: Implications for sleep quality, academic performance, and subjective well-being. Computers in Human Behavior, 52, 450-457.

https://doi.org/10.1016/j.chb.2015.06.021

Livingstone, S., Haddon, L., Görzig, A., Ólafsson, K. (2011) Risks and safety on the internet: the perspective of European children: Full findings and policy implications from the EU Kids Online survey of 9-16 year olds and their parents in 25 countries. Deliverable D4. London: LSE/EU Kids Online. Retrieved from http://eprints.Ise.ac.uk/33731/

Livingstone, S., \& Helsper, E. (2008). Parental mediation and children's Internet use. Journal of Broadcasting \& Electronic Media, 52, 581-599. https://doi.org/10.1080/08838150802437396

Livingstone, S., Mascheroni, G., \& Staksrud, E. (2015). Developing a framework for researching children's online risks and opportunities in Europe. London: LSE/EU Kids Online. Retrieved from http://eprints.Ise.ac.uk/64470/

Livingstone, S., Ólafsson, K., Helsper, E.J., Lupiáñez-Villanueva, F., Veltri, G.A., \& Folkvord, F. (2017). Maximizing opportunities and minimizing risks for children online: The role of digital skills in emerging strategies of parental mediation. Journal of Communication, 67, 82-105. https://doi.org/10.1111/jcom.12277

Livingstone, S., \& Smith, P. K. (2014). Annual research review: Harms experienced by child users of online and mobile technologies: The nature, prevalence and management of sexual and aggressive risks in the digital age. Journal of Child Psychology and Psychiatry, 55, 635-654. https://doi.org/10.1111/jcpp.12197

Mathers, M., Canterford, L., Olds, T., Hesketh, K., Ridley, K., \& Wake, M. (2009). Electronic media use and adolescent health and well-being: Cross-sectional community study. Academic Pediatrics, 9, 307-314. https://doi.org/10.1016/j.acap.2009.04.003

Mendoza, K. (2009). Surveying parental mediation: Connections, challenges and questions for media literacy. The Journal of Media Literacy Education, 1, 28-41.

Nederlands Jeugdinstituut (2017). Cijfers over jeugd en opvoeding: Leerlingen per onderwijssoort [Data on youth and education: Students per type of educational level]. Utrecht: Nederlands Jeugdinstituut. Retrieved from https://www.nji.nl/nl/Databank/Cijfers-over-Jeugd-en-Opvoeding/Cijfers-per-onderwerp/Jeugd---algemeen 
Nikken, P. (2017b). Implications of low or high media use among parents for young children's media use. Cyberpsychology: Journal of Psychosocial Research on Cyberspace, 11(3), article 1.

https://dx.doi.org/10.5817/CP2017-3-1

Nikken, P., \& Jansz, J. (2007). Playing restricted videogames: Relations with game ratings and parental mediation. Journal of Children and Media, 1, 227-243. https://doi.org/10.1080/17482790701531862

Ofcom (2017). Children and parents: Media use and attitudes report 2017. London, UK: Ofcom.

Portnuff, C. D. F., Fligor, B. J., \& Arehart, K. H. (2011). Teenage use of portable listening devices: A hazard to hearing? Journal of the American Academy of Audiology, 22, 663-677. https://doi.org/10.3766/jaaa.22.10.5

Radesky, J. \& Christakis, D. (2016). Media and young minds. Pediatrics, AAP News and Journals Council on Communications and Media. Retrieved from:

http://pediatrics.aappublications.org/content/early/2016/10/19/peds.2016-2591

Rideout, V. (2017). The Common Sense Census: Media use by kids zero to eight. San Fransico CA: Common Sense Media.

Stelling-Kończak, A., Hagenzieker, M., Van Wee, B. (2015). Traffic sounds and cycling safety: The use of electronic devices by cyclists and the quietness of hybrid and electric cars. Transport Reviews, 35, 422-444.

https://doi.org/10.1080/01441647.2015.1017750

Straker, L., Abott, R., Collins, R., \& Campbell, A. (2014). Evidence-based guidelines for wise use of electronic games by children. Ergonomics, 57, 471-489. https://doi.org/10.1080/00140139.2014.895856

Sweeting, H. \& Hunt, K. (2014). Adolescent socio-economic and school-based social status, health and well-being. Social Science \& Medicine, 121, 39-47. https://doi.org/10.1016/j.socscimed.2014.09.037

Tabachnick, B. G., \& Fidell, L. S. (2007). Using multivariate statistics (5 $5^{\text {th }}$ ed.). Essex, UK: Pearson.

Touitou, Y., Touitou, D., \& Reinberg, A. (2016). Disruption of adolescents' circadian clock: the vicious circle of media use, exposure to light at night, sleep loss and risk behaviors. Journal of Physiology Paris, 110, 467-479. https://doi.org/10.1016/j.jphysparis.2017.05.001

Valkenburg, P. M. \& Piotrowski, J. T. (2017). Plugged in: How media attract and affect youth. New Haven: Yale University Press.

Valkenburg, P. M., Piotrowski, J. T., Hermanns, J., \& de Leeuw, R. (2013). Development and validation of the perceived parental media mediation scale: A self-determination perspective. Human Communication Research, 39, 445-469. https://doi.org/10.1111/hcre.12010

van den Eijnden, R. J., Spijkerman, R., Vermulst, A. A., van Rooij, T. J., \& Engels, R. C. (2010). Compulsive internet use among adolescents: Bidirectional parent-child relationships. Journal of Abnormal Child Psychology, 38, 77-89. https://doi.org/10.1007/s10802-009-9347-8

Vigna-Taglianti, F., Brambilla, R., Priotto, B., Angelino, R., Cuomo, G. L., \& Diecidue R. (2017). Problematic internet use among high school students: Prevalence, associated factors and gender differences. Psychiatry Research, 257, 163-171. https://doi.org/10.1016/j.psychres.2017.07.039

Vogel, I., Verschuure, H., van der Ploeg, C. P. B., Brug, J., \& Raat, H. (2009). Adolescents and MP3 players: Too many risks, too few precautions. Pediatrics, 123, e953-e958. https://doi.org/10.1542/peds.2008-3179 
Weintraub Austin, E., \& Pinkleton, B. E. (2001). The role of parental mediation in the political socialization process. Journal of Broadcasting \& Electronic Media, 45, 221-240. https://doi.org/10.1207/s15506878jobem4502_2

\section{Correspondence to:}

Prof. dr. Peter Nikken

Windesheim university of applied science

Postbus 10090

8000 GB Zwolle

088- 4696168

p.nikken(at)windesheim.nl

Editorial record: First submission received on October 11, 2017. Revisions received on July 12, 2018, August 8, 2018, and September 27, 2018. Accepted for publication on October 4, 2018.

The article is part of the Special Issue "Health and Technology" guest edited by Michal Molcho (NUI Galway), Christine Pellegrini (University of South Carolina), and Jana Holubcikova (PJ Safarik University).

\section{About Author}

Peter Nikken, PhD, is Lector of Child and media at Windesheim University for applied science, Professor at the Erasmus University Rotterdam, School of History, Culture and Communication, and affiliated to the Netherlands Youth Institute. His research interests include media literacy and media education, the beneficial and negative effects of media on children and adolescents, and the mediating role of parents and other co-educators. 